\title{
ENRAIZAMENTO DE SEGMENTOS NODAIS CAULINARES DE FIGUEIRA (1)
}

\author{
DAIANA RAQUEL PAULETTI $\left({ }^{2}\right)$; RAFAEL PIO $\left(3^{*}\right)$; WILSON BARBOSA $\left({ }^{4}\right)$; \\ EDVAN ALVES CHAGAS $\left({ }^{5}\right)$; TAILENE ELISA KOTZ $\left(^{2}\right)$
}

\begin{abstract}
RESUMO
Visando aumentar o rendimento de mudas de figueira objetivou-se neste trabalho estudar o enraizamento de segmentos nodais caulinares, utilizando-se diferentes concentrações de AIB (ácido indolbutírico) e ferimentos entre os nós da estaca. Estacas caulinares da porção mediana de figueira 'Roxo de Valinhos' foram coletadas por ocasião da poda hibernal (julho), padronizadas com $20 \mathrm{~cm}$ de comprimento, diâmetro de $12 \mathrm{~mm}$ e cinco nós. Em metade das estacas, realizou-se um ferimento entre os nós [cortes quadrados com dimensões de $1(\mathrm{um}) \mathrm{cm}$ ]. As estacas foram tratadas com diferentes concentrações de $\operatorname{AIB}\left(0,1.000,2.000\right.$ e $\left.3.000 \mathrm{mg} \mathrm{L}^{-1}\right)$, e enterradas na posição horizontal, a $5 \mathrm{~cm}$ de profundidade, permanecendo totalmente imersas, em leito de areia umedecido, sob telado (sombrite com 50\% de luminosidade). Passados 90 dias, mensurou-se a porcentagem de estacas enraizadas e brotadas, o comprimento médio das brotações, a porcentagem de nós enraizados, número médio de raízes e brotações por estaca e por nó e o rendimento de mudas (número médio de nós enraizados e simultaneamente brotados, por estaca). O enraizamento dos segmentos nodais caulinares é uma alternativa para o aumento no rendimento de mudas de figueira, devendo-se causar ferimento entre os nós e aplicação de $2000 \mathrm{mg} \mathrm{L}^{-1}$ de AIB.
\end{abstract}

Palavras-chave: Ficus carica L.; propagação vegetativa; ácido indolbutírico.

\section{ABSTRACT}

ROOTING OF NODAL SEGMENTS OF FIG TREE

The aim of this work was to increase the rooting of stem nodal segments of tree seedling using different concentrations of IBA and injuries between the knots. Stem cuttings of fig tree 'Roxo de Valinhos' were collected at the moment of the hibernal pruning (July), standardized with $20 \mathrm{~cm}$ in length, diameter of $12 \mathrm{~mm}$ and five knots. In half of the stakes, an injury was done between the knots [square cuts with dimensions of 1 (one) $\mathrm{cm}$ ]. The stakes were treated with different concentrations of $\operatorname{IBA}\left(0,1.000,2.000\right.$ and $\left.3.000 \mathrm{mg} \mathrm{L}^{-1}\right)$ and fully buried in the horizontal position at $5 \mathrm{~cm}$ of depth in moist sand under nursery (50\% of brightness) condition. After 90 days, the rooting and sprouting of stakes, the length of shoots, the rooted nodes, number of roots and shoots per cutting and knot and yield of seedlings (average number of nodes rooted in sprouted cuttings) were evaluated. The rooting of nodal segments is an alternative for increasing the rooting of fig tree seedlings, being indicated an injury between knots associated to the application of $2000 \mathrm{mg} \mathrm{L}^{-1}$ of IBA.

Key words: Ficus carica L.; vegetative propagation; indolebutiric acid.

(1) Recebido para a publicação em 16 de setembro de 2008 e aceito em 9 de março de 2010.

(2) Universidade Estadual do Oeste do Paraná (Unioeste), Rua Pernambuco, 1777, Caixa Postal 1008, Centro, 85960-000 Marechal Cândido Rondon (PR). E-mail: daianarpauletti@yahoo.com.br taileneelisa@hotmail.com

$\left(^{3}\right)$ Universidade Federal de Lavras (UFLA), Departamento de Agricultura, Caixa Postal 3037, 37200-000 Lavras (MG). Bolsista Produtividade em Pesquisa CNPq. E-mail: rafaelpio@dag.ufla.br $\left(^{*}\right)$ Autor correspondente

$\left(^{4}\right)$ Instituto Agronômico (IAC), Centro Experimental Central, Caixa Postal 28, 13001-970 Campinas (SP). Bolsista Produtividade em Pesquisa CNPq. E-mail: wbarbosa@iac.sp.gov.br

$\left(^{5}\right)$ Empresa Brasileira de Pesquisa Agropecuária (EMBRAPA Roraima), Rodovia 174, Km 8, Caixa Postal 133, $69301-970$ Boa Vista (RR). Bolsista Produtividade em Pesquisa CNPq. E-mail: echagas@cpafrr.embrapa.br 
Como alternativa para a propagação da figueira, pode-se utilizar o enraizamento das estacas de menor comprimento em ambiente protegido, propiciando a seleção de plantas de qualidade.

Nesse procedimento de propagação, as estacas de figueira são colocadas na posição vertical, enterrando-se no máximo a metade do comprimento da estaca no leito de enraizamento (OJima e Rigitano, 1969; NogueIRA et al., 2007). No entanto, os índices de enraizamento das estacas coletadas na época da poda hibernal da figueira está em torno de 50\% (NoRBERTO et al., 2001). O baixo enraizamento dos propágulos vegetativos pode estar correlacionado a fatores intrínsecos do material vegetal, como a idade do tecido, o tipo e a época de coleta das estacas, a concentração de fitormônios, ou a fatores exógenos, como as condições de cultivo das estacas (FACHINELLO et al., 2005).

Uma vertente ao enraizamento das estacas caulinares da figueira seria a utilização de segmentos nodais, que consiste em colocar estacas caulinares totalmente submersas na posição horizontal, em leito de enraizamento. Como em cada nó da porção mediana do caule da figueira são encontradas gemas vegetativas, em estado de dormência, e o enraizamento da porção caulinar ocorre em toda a extensão da estaca e não somente na base (Pıo et al., 2006), esse método poderá aumentar o número de mudas em cinco vezes, já que, em estacas medianas, a distância dos entrenós é de $4 \mathrm{~cm}$. Enquanto em uma única estaca de $20 \mathrm{~cm}$ pelo método convencional da estaquia, em leito de enraizamento, consegue-se uma muda somente, pelo enraizamento de segmentos nodais poderá se conseguir cinco mudas.

O sucesso desse método de propagação poderá auxiliar na rápida multiplicação de estacas de novos cultivares de figueira introduzidos de outros países, uma vez que, em programas de melhoramento genético, visando à introdução e avaliação de novos cultivares, geralmente o número de propágulos vegetativos cedidos são em número reduzido, o que onera os trabalhos de seleção varietal, diante do longo período demandado na multiplicação das cultivares.

Osucesso da multiplicaçãode propágulos caulinares de figueira pelo método de segmentos nodais vai auxiliar os programas de introdução e avaliação agronômica de novas cultivares no Brasil, pois, na atualidade, há apenas um único cultivar em escala comercial, o 'Roxo de Valinhos', com sérios problemas fitossanitários, e dentre as principais enfermidades, podem-se citar os nematóides (Meloidogyne incógnita e Heterodera fici), a ferrugem da figueira (Cerotelium fici) e a seca-da-mangueira (Ceratocystis fimbriata Ell. \& Halst.) (RiBeIRO, 1999).

O ferimento entre os nós da estacas poderá aumentar o contato e a absorção do ácido indolbutírico, sendo a concentração desse fitormônio determinante no sucesso do enraizamento de segmentos nodais de figueira. Diante do exposto, objetivou-se verificar o aumento no rendimento de mudas de figueira, através do enraizamento de segmentos nodais caulinares, utilizando-se diferentes concentrações de ácido indolbutírico (AIB) e ferimentos entre os nós da estaca.

Estacas caulinares de figueira 'Roxo de Valinhos' foram coletadas em um plantio comercial no momento de poda hibernal (julho), aproveitando-se apenas a porção mediana dos ramos, padronizando as estacas com $20 \mathrm{~cm}$ de comprimento, diâmetro ao redor de 12 $\mathrm{mm}$ e cinco nós, efetuando-se um corte reto em ambas as extremidades das estacas.

Em metade das estacas, realizou-se um ferimento entre os nós (cortes quadrados com dimensões de um centímetro), com auxílio de canivete. Posteriormente, as estacas foram tratadas com diferentes concentrações de AIB (1.000, 2.000 e $3.000 \mathrm{mg} \mathrm{L}^{-1}$ ), além da testemunha (ausente de tratamento), através do pincelamento das referidas concentrações, com auxílio de um pincel de cerdas finas, entre os nós das estacas. As estacas foram enterradas na posição horizontal a $5 \mathrm{~cm}$ de profundidade, permanecendo totalmente imersas, em leito de areia umedecido, sob telado constituído de sombrite com 50\% de luminosidade. Durante o período do experimento, o leito de enraizamento foi sistematicamente umedecido.

$\mathrm{O}$ delineamento utilizado foi $\mathrm{o}$ inteiramente casualizado, no esquema fatorial $2 \times 4$, sendo o primeiro fator constituído pela presença ou ausência de ferimento e o segundo fator pelas concentrações de AIB, com quatro repetições e 10 estacas por unidade experimental, perfazendo um montante de 320 estacas. Passados 90 dias, as estacas foram removidas do leito de enraizamento e mensurou-se a porcentagem de estacas enraizadas e brotadas, o comprimento médio das brotações, a porcentagem de nós enraizados, o número médio de raízes e brotações por estaca e por nó, além do rendimento de mudas (número médio de nós enraizados e simultaneamente brotados, por estaca).

Os dados foram submetidos à análise de variância, as médias comparadas pelo teste Tukey, ao nível de $5 \%$ de probabilidade e as concentrações de AIB e a interação entre os fatores, submetidas à regressão, segundo as recomendações de GoMEs (2000). As análises foram realizadas pelo programa computacional Sistema para Análise de Variância - SISVAR.

Não houve diferenças entre a porcentagem de estacas enraizadas e brotadas e do comprimento médio da brotação entre os tratamentos testados. No entanto, salienta-se o sucesso do enraizamento e da brotação das estacas caulinares de figueira, por intermédio da utilização dos segmentos nodais totalmente submersos no leito de enraizamento, obtendo-se $100 \%$ de 
enraizamento e no mínimo 92\% de brotação nas estacas (Tabela 1).

O resultado do porcentual de enraizamento das estacas vem a superar o enraizamento convencional de estacas de figueira em ambiente protegido (estacas enterradas na posição vertical e aprofundadas em metade de seu comprimento no leito de enraizamento), que, em média, não ultrapassam 50\% de enraizamento (Norberto et al., 2001).

Para o número médio de nós enraizados, obtevese maior enraizamento na ausência do tratamento com o fitorregulador e em estacas que não tiveram ferimento (55\%); porém, para as estacas com ferimento entre os nós obteve-se $40 \%$ de enraizamento sem o tratamento com AIB e com a utilização de $2.000 \mathrm{mg} \mathrm{L}^{-1}$ de AIB, esse índice aumentou para 100\% (Figura 1a).

Quanto ao número médio de raízes por estaca, foram registradas 22 raízes sem o tratamento com $\mathrm{AIB}$, em estacas sem ferimento; porém, submetendo-se as estacas nas concentrações crescentes desse fitorregulador, houve aumento linear na formação de raízes, com a emissão de 65 raízes com à utilização de $3.000 \mathrm{mg} \mathrm{L}^{-1}$ de AIB, aumento de $27 \%$ em comparação com a utilização de $2.000 \mathrm{mg}$ $\mathrm{L}^{-1}$ (Figura 1b). Bons resultados foram adquiridos para o número médio de raízes por estaca com a adoção do ferimento entre os nós da estaca e com a aplicação de $2.000 \mathrm{mg} \mathrm{L}^{-1}$ de AIB, com aumento de 194 raízes em comparação com a ausência de AIB (Figura 1b).

Na tentativa de aumentar o rendimento de mudas através da técnica de enraizamento dos segmentos nodais em figueira, os resultados rizogênicos foram significativos, em se tratando da avaliação do número médio de raízes por nós. Em estacas sem ferimentos e tratadas com $3.000 \mathrm{mg} \mathrm{L}^{-1}$ de AIB, notaram-se 26 raízes a mais que a testemunha; para estacas com ferimentos, a diferença entre a não-utilização de AIB e a concentração de $2.000 \mathrm{mg} \mathrm{L}^{-1}$ foi de 32 raízes por nó (Figura 1c).

OHLAND et al. (2009), trabalhando com o enraizamento de estacas caulinares lenhosas de figueira 'Roxo de Valinhos', registraram apenas 10,4 raízes por estacas, com ausência de AIB. No entanto, com a utilização de $2.000 \mathrm{mg} \mathrm{L}^{-1}$ de AIB, aplicado na base de estacas caulinares lenhosas oriundas da porção apical dos ramos de figueira 'Roxo de Valinhos', o número de raízes por estaca foi de 16,13 (Pio et al., 2006).

$\mathrm{Na}$ estaquia, muitas vezes, a aplicação de fitorreguladores é decisiva para a formação de raízes e tem por finalidade aumentar a porcentagem de estacas que formam raízes, acelerar sua iniciação, aumentar o número e a qualidade das raízes formadas e uniformizar o enraizamento (FACHINELLO et al., 2005).

Com o uso de ferimento na base da estaca submersa ao leito de enraizamento e a aplicação de fitorreguladores, ou sinergismo das duas técnicas, têm se verificado bons resultados para espécies de difícil enraizamento, pois, as incisões expõem o câmbio e a região do córtex, aumentando assim a interação com o regulador vegetal (HOWARD et al., 1984; HARTMANN et al., 2002). As lesões nos tecidos estimulam a divisão celular, possivelmente por romper a barreira física exercida pelos anéis de esclerênquima, aumentando a taxa respiratória e, consequentemente, a produção de primórdios radiculares, diante do acúmulo de carboidratos, auxinas e síntese de etileno nessa região lesada (HARTMANN et al., 2002; FACHINELlo et al., 2005). MurATA et al. (2002) aumentaram em $16,8 \%$ o enraizamento de estacas lenhosas do porta-enxerto de pereira 'Taiwan Nachi-C' com a técnica de incisão na base das estacas.

O sucesso rizogênico da técnica de enraizamento de segmentos nodais caulinares totalmente submersos no leito de enraizamento, na posição horizontal, pode estar associado ao aumento da superfície de contato da estaca com a umidade do leito de enraizamento, diante da exposição de toda a extensão da estaca. PıO et al. (2003), estudando diferentes profundidades de plantio no enraizamento de estacas caulinares lenhosas de figueira, concluíram em seu trabalho que estacas totalmente submersas no substrato, na posição vertical, proporcionam os maiores índices de enraizamento.

Outra explicação para o sucesso desse método de propagação pode estar associada ao fato de as estacas permanecerem na ausência de luz, ficando totalmente submersas no leito de enraizamento. O estiolamento promove alterações no conteúdo de compostos fenólicos que desempenham importante papel no metabolismo de auxinas, atuando como cofatores (da auxina) e agindo

Tabela 1. Porcentagem de estacas enraizadas e brotadas e comprimento médio das brotações (cm) de estacas caulinares de figueira 'Roxo de Valinhos' (Ficus carica L.) através do enraizamento de segmentos nodais

\begin{tabular}{lccc}
\hline & & Variáveis analisadas & \\
\cline { 2 - 4 } Ferimento & Estacas enraizadas & Estacas brotadas & $\begin{array}{c}\text { Comprimento médio da brotação } \\
\text { por estaca }\end{array}$ \\
\hline Sem ferimento & $\%$ & $\%$ & $2,38^{\mathrm{ns}}$ \\
Com ferimento & $100^{\mathrm{ns}}$ & $100^{\mathrm{ns}}$ & 2,71 \\
C.V.(\%) & 100 & 92 & 26,12 \\
\hline
\end{tabular}

ns: não significativo, segundo o teste F. 

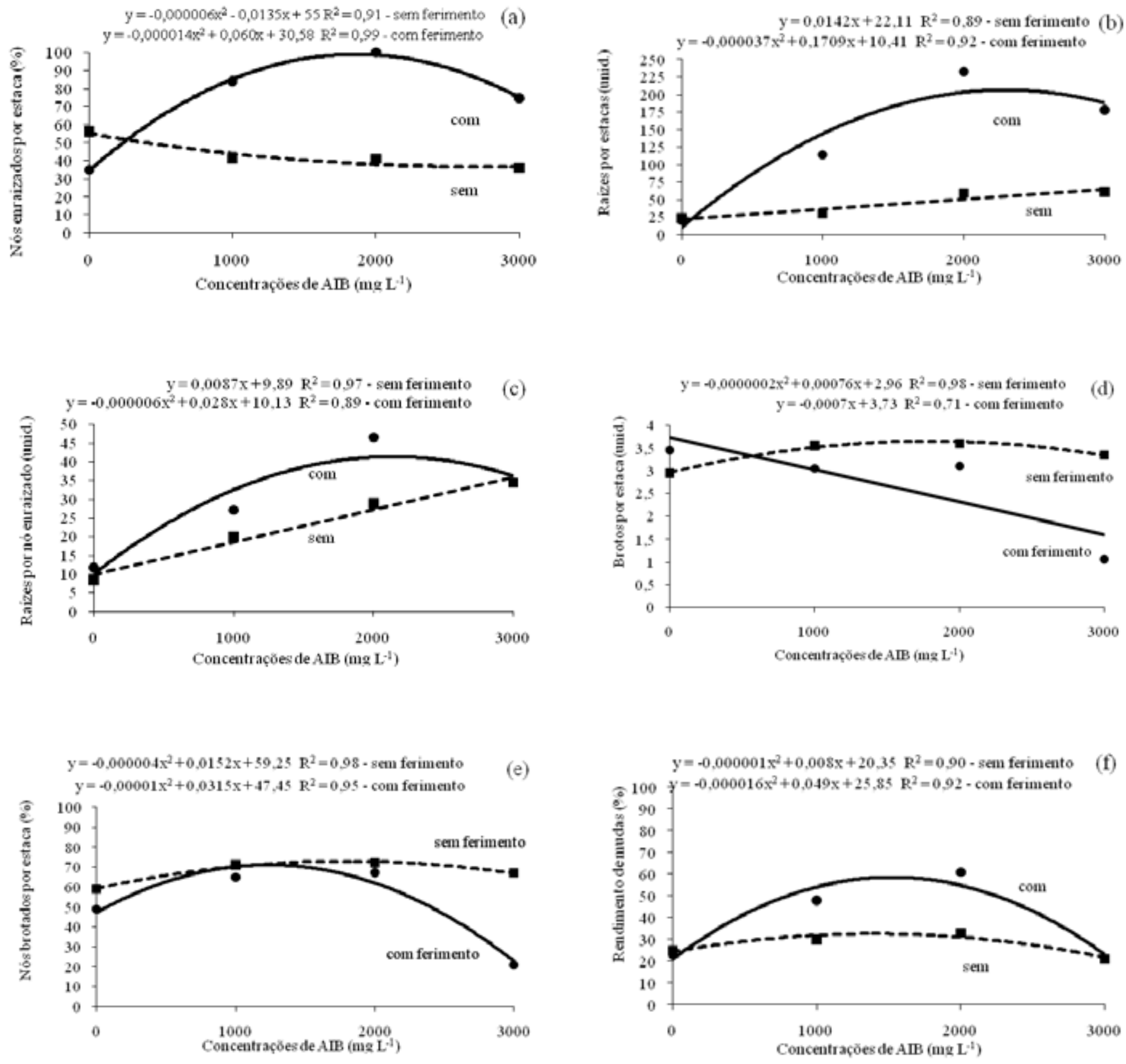

Figura 1. Porcentagem média de nós enraizados por estaca (a), número médio de raízes por estaca (b), número médio de raízes por nó enraizado (c), número médio de brotos por estaca (d), porcentagem média de nós brotados por estaca (e) e porcentagem de rendimento de mudas (f) de figueira 'Roxo de Valinhos' (Ficus carica L.) através do enraizamento de segmentos nodais, utilizando-se diferentes concentrações de AIB e ferimentos entre os nós.

como inibidores da AIA-oxidase, que é o complexo enzimático responsável pela degradação das auxinas (HARTMANN et al., 2002).

Com relação à emissão de brotações, houve aumento para estacas que não sofreram ferimentos e uso de $2.000 \mathrm{mg} \mathrm{L}^{-1}$ de AIB (Figura 1d). Para as estacas que receberam ferimento, os melhores resultados foram adquiridos na ausência de AIB, decaindo linearmente o número médio de brotos por estaca, à medida que se aumentou as concentrações do fitorregulador (Figura 1d).

A redução da emissão de brotações em estacas com ferimento pode estar correlacionada ao esgotamento das reservas endógenas na estaca, em função do elevado número de raízes emitidas com exposição ao AIB. Para a porcentagem média de nós brotados, tanto para estacas com ou sem ferimentos, ocorreu tendência de obtenção dos melhores resultados com a utilização 
de $2.000 \mathrm{mg} \mathrm{L}^{-1}$ de AIB (Figura 1e). Esse resultado possivelmente decorre do desencadeamento de uma série de atividades ocasionadas pela presença exógena da auxina AIB, ao estímulo rizogênico da estaca.

O rendimento de mudas elevou-se pela ocorrência simultânea de nós enraizados e brotados e a utilização de $2.000 \mathrm{mg} \mathrm{L}^{-1}$ de AIB, independente do ferimento na estaca. Porém, obteve-se $60 \%$ de rendimento de mudas, com a utilização da concentração de AIB mencionada e se adotando a utilização de ferimento entre os nós (Figura 1f).

Esse processo significa, em caráter prático, que, com a adoção da técnica de enraizamento de segmentos nodais, na propagação da figueira, triplicase o rendimento de mudas. Esses resultados são úteis e aplicáveis na rápida multiplicação de novas cultivares, auxiliando programas de melhoramento genético da frutífera em questão, via introdução e multiplicação em larga escala dos propágulos advindos de outros países.

Com os resultados do presente experimento, comprovou-se a validação da técnica de enraizamento de segmentos nodais caulinares da figueira. No preparo das estacas, deve-se efetuar o ferimento entre os nós e aplicar a concentração de $2.000 \mathrm{mg} \mathrm{L}^{-1}$ de AIB.

\section{REFERÊNCIAS}

FACHINELLO, J.C.; HOFFMANN, A.; NACHTIGAL, J.C. Propagação de plantas frutíferas. Brasília: Embrapa, 2005. 221p.

GOMES, F.P. Curso de estatística experimental. 14 ed. Piracicaba: USP/ESALQ, 2000. 477p.

HARTMANN, H.T.; KESTER, D.E.; DAVIES JUNIOR, F.T;; GENEVE, R.L. Plant propagation: principles and practices. 7. ed. New Jersey: Prentice Hall, 2002. 880p.

HOWARD, B.H.; HARRISON-MURRAY, R.S.; MALKENZIE, K.A.D. Rooting responses to wouding winter cutting of 'EM-
26' apple rootstock. Journal of Horticultural Science, v.59, p.131-139, 1984.

MURATA, I.M.; BARBOSA, W.; NEVES, C.S.V.J.; FRANCO, J.A.M. Enraizamento de estacas lenhosas de porta-enxertos de pereira sob nebulização intermitente. Revista Brasileira de Fruticultura, v.24, p.583-585, 2002.

NOGUEIRA, A.M.; CHALFUN, N.N.J.; DUTRA, L.F.; VILLA, F. Propagação de figueira (Ficus carica L.) por meio de estacas retiradas durante o período de vegetação. Ciência e Agrotecnologia, v.31, p.914-920, 2007.

NORBERTO, P.M.; CHALFUN, N.N.J.; PASQUAL, M.; VEIGA, R.D.; PEREIRA, G.E.; MOTA, J.H. Efeito da época de estaquia e do AIB no enraizamento de estacas de figueira (Ficus carica L.). Ciência e Agrotecnologia, v.25, p.533-541, 2001.

OHLAND, T.; PIO, R.; CHAGAS, E.A.; BARBOSA, W.; DALASTRA, I.M.; KOTZ, T.E. Enraizamento de estacas apicais lenhosas de figueira 'Roxo de Valinhos' com a aplicação de AIB e cianamida hidrogenada. Revista Brasileira de Fruticultura, v.31, 273-279, 2009.

OJIMA, M.; RIGITANO, O. Influência da época e profundidade de plantio no enraizamento de estacas de figueira. Bragantia, v.28, p.255-260, 1969.

PIO, R.; GONTIJO, T.C.A.; CARRIJO, E.P.; VISIOLI, E.L.; TOMASETTO, F.; CHALFUN, N.N.J.; RAMOS, J.D. Enraizamento de estacas apicais de figueira em diferentes acondicionamentos e ambientes distintos. Revista Brasileira de Agrociência, v.9, p.357-360, 2003.

PIO, R.; RAMOS, J.D.; CHALFUN, N.N.J.; GONTIJO, T.C.A.; MENDONÇA, V.; CARRIJO, E.P.; CHAGAS, E.A. Propagação de estacas apicais de figueira: diferentes ambientes, ácido indolbutírico e tipo de estaca. Ciência e Agrotecnologia, v.30, p.1021-1026, 2006.

RIBEIRO, I.J.A. Doenças da figueira. In: CORRÊA, L.S.; BOLIANI, A.C. (Ed.). $1^{\circ}$ Simpósio Brasileiro Sobre a Cultura da Figueira. Ilha Solteira: Unesp, 1999. p.151-164. 
